\title{
Predictive properties of different multidimensional staging systems in patients with chronic obstructive pulmonary disease
}

This article was published in the following Dove Press journal:

International Journal of COPD

10 October 2011

Number of times this article has been viewed

\section{Toru Oga'}

Mitsuhiro Tsukino ${ }^{2}$

Takashi Hajiro ${ }^{3}$

Akihiko $\mathrm{Ikeda}^{4}$

Koichi Nishimura ${ }^{5}$

'Department of Respiratory Care and Sleep Control Medicine, Graduate School of Medicine, Kyoto University, Kyoto, Japan; ${ }^{2}$ Department of Respiratory Medicine, Hikone Municipal Hospital, Hikone, Japan; ${ }^{3}$ Department of Respiratory Medicine, Tenri Hospital, Tenri, Japan; ${ }^{4}$ Department of Respiratory Medicine, Nishi-Kobe Medical Center, Kobe, Japan; ${ }^{5}$ Department of Respiratory Medicine, Rakuwakai Otowa Hospital, Kyoto, Japan
Correspondence:Toru Oga

Department of Respiratory Care and Sleep Control Medicine, Graduate

School of Medicine, Kyoto University,

54, Kawahara, Shogoin, Sakyo-ku,

Kyoto, 606-8507, Japan

$\mathrm{Tel}+8 \mathrm{I} 7575 \mathrm{I} 3852$

Fax +8I 757513854

E-mail ogato@kuhp.kyoto-u.ac.jp
Background: Chronic obstructive pulmonary disease (COPD) is considered to be a respiratory disease with systemic manifestations. Some multidimensional staging systems, not based solely on the level of airflow limitation, have been developed; however, these systems have rarely been compared.

Methods: We previously recruited 150 male outpatients with COPD for an analysis of factors related to mortality. For this report, we examined the discriminative and prognostic predictive properties of three COPD multidimensional measurements. These indices were the modified BODE (mBODE), which includes body mass index, airflow obstruction, dyspnea, and exercise capacity; the ADO, composed of age, dyspnea, and airflow obstruction; and the modified DOSE (mDOSE), comprising dyspnea, airflow obstruction, smoking status, and exacerbation frequency.

Results: Among these indices, the frequency distribution of the mBODE index was the most widely and normally distributed. Univariate Cox proportional hazards analyses revealed that the scores on three indices were significantly predictive of 5-year mortality of COPD $(P<0.001)$. The scores on the mBODE and ADO indices were more significantly predictive of mortality than forced expiratory volume in 1 second, the Medical Research Council dyspnea score, and the St. George's Respiratory Questionnaire total score. However, peak oxygen uptake on progressive cycle ergometry was more significantly related to mortality than the scores on the three indices $(P<0.0001)$.

Conclusion: The multidimensional staging systems using the mBODE, ADO, and mDOSE indices were significant predictors of mortality in COPD patients, although exercise capacity had a more significant relationship with mortality than those indices. The mBODE index was superior to the others for its discriminative property. Further discussion of the definition of disease severity is necessary to promote concrete multidimensional staging systems as a new disease severity index in guidelines for the management of COPD.

Keywords: COPD, multidimensional staging systems, BODE index, ADO index, DOSE index

\section{Background}

Chronic obstructive pulmonary disease (COPD) is now considered as a respiratory disease with systemic manifestations. ${ }^{1}$ COPD first affects the lungs primarily, and then structural and functional changes also take place in other organs. The degree of airflow limitation as defined by forced expiratory volume in 1 second $\left(\mathrm{FEV}_{1}\right)$ has been used as an index of disease severity, partly because of its significant relationship with mortality. ${ }^{2,3}$ Guidelines indicate that some multidimensional staging systems including systemic components in addition to airflow limitation may be used to assess 
disease severity, ${ }^{1,4}$ although the definition of disease severity remains elusive.

The BODE index, incorporating measurements of nutrition, airflow limitation, dyspnea, and exercise capacity, has been established for multidimensional staging. ${ }^{5}$ It is useful in predicting mortality and hospitalizations and in reflecting disease modification and progression. ${ }^{6}$ More simplified indices such as the ADO index, composed of age, dyspnea, and airflow limitation, ${ }^{7}$ and the DOSE index, composed of dyspnea, airflow limitation, smoking status, and exacerbation frequency, ${ }^{8}$ have been developed recently and have been validated. In two European cohorts, both the ADO index and the updated BODE index significantly predicted the 3-year mortality risk after the first hospital admission due to an exacerbation of moderate-to-severe COPD, although the original BODE index did not accurately predict such a risk. $^{7}$ The DOSE index was related to a range of clinically important outcomes of COPD such as health status, hospital admission, or respiratory failure, and was predictive of exacerbations. ${ }^{8}$ Although some multidimensional staging systems have been developed recently, these indices have rarely been compared.

More information about the properties of these indices or relationships is needed so that they can be better used in clinical practice or trials and, furthermore, be adopted concretely in the guidelines in future. We hypothesized that the BODE, ADO, and DOSE indices would be useful as predictors of mortality in COPD, but that they would have some different characteristics. We previously examined the factors related to 5-year mortality using multiple measurements in patients with COPD. ${ }^{9}$ In the present study, by reviewing those data, we analyzed the discriminative and predictive properties of those multidimensional indices in patients with COPD.

\section{Materials and methods Patients}

We previously recruited 150 consecutive male outpatients with COPD and analyzed factors related to mortality. ${ }^{9}$ Entry criteria included (1) smoking history of more than 20 pack-years, (2) maximal $\mathrm{FEV}_{1} /$ forced vital capacity ratio of less than 0.7 and prebronchodilator $\mathrm{FEV}_{1}$ of less than $80 \%$ of the predicted value, (3) regular attendance at Kyoto University, Kyoto, Japan, outpatient clinic over 6 months, (4) no uncontrolled comorbidities, and (5) no COPD exacerbations over the preceding 6 weeks. The study protocol was approved by the institutional ethical committee of Kyoto University.

\section{Measurements}

Pulmonary function tests were performed at least 12 hours after the withdrawal of inhaled bronchodilators. ${ }^{9}$ Patients performed spirometry at 15 and 60 minutes after inhaling salbutamol $(400 \mu \mathrm{g})$ and ipratropium bromide $(80 \mu \mathrm{g})$ using a metered-dose inhaler with a spacer device.

Exercise tests were performed on symptom-limited progressive cycle ergometry 60 minutes after the inhalation of bronchodilators as described in detail previously. ${ }^{9-11}$ Patients wore a face mask and began unloaded pedaling for 3 minutes, after which the workload was increased progressively by an increment of $1 \mathrm{~W}$ every 3 seconds to the limit of tolerance. The exercise data were recorded with an automated exercise testing system. Peak oxygen uptake $\left(\dot{\mathrm{V}}_{2}\right)$ that was reached during exercise was calculated. Predicted values were calculated using the standard equation. ${ }^{12,13}$

Dyspnea was evaluated by the Japanese version of the modified Medical Research Council (MRC) dyspnea scale, which is a 5-point scale (0-4) based on degrees of various physical activities that precipitate dyspnea. ${ }^{14,15}$ Higher scores on the MRC indicate more severe dyspnea. Health status was assessed by the Japanese version of the St. George's Respiratory Questionnaire (SGRQ). ${ }^{9,16,17}$ The SGRQ consists of 50 items divided into the three components of symptoms, activity, and impacts, and the total score was calculated with scores ranging from 0 to 100 . Higher scores on the SGRQ indicate a more severe health status.

\section{Multidimensional staging}

The BODE index was principally based on the original report $^{5}$ whose score comprises the body mass index (BMI), percentage of the predicted $\mathrm{FEV}_{1}$, dyspnea by the MRC, and 6-minute walking distance (6MWD) as an exercise capacity component. Scores ranged from 0 (best status) to 3 (worst status) for $\mathrm{FEV}_{1}$ and $\mathrm{MRC}$, and 0 or 1 for BMI. In the present study, we employed the modified BODE index (mBODE), which used $\dot{\mathrm{V}}_{2}$ as \% predicted, as tested by the progressive cycle ergometry instead of the $6 \mathrm{MWD}$, and was previously developed and validated. ${ }^{18,19}$ The $\%$ predicted was scored as follows: score 0 for $>70 \%$ predicted, score 1 for $60 \%-69 \%$ predicted, score 2 for $40 \%-59 \%$ predicted, and score 3 for $40<\%$ predicted. Points for each component were added together so that the mBODE index ranged from 0 to 10 .

The ADO index was calculated based on the original report, ${ }^{7}$ with the score comprising age, dyspnea by the $\mathrm{MRC}$, and $\mathrm{FEV}_{1}$. Scores ranged from 0 (best status) to 5 (worst status) for age, 0-3 for MRC, and 0-2 for $\mathrm{FEV}_{1}$. Points for each component were added so that the ADO index ranged from 0 to 10 . 
The DOSE index was calculated primarily based on the original report, ${ }^{8}$ with scores comprising dyspnea by the MRC, $\mathrm{FEV}_{1}$, smoking status, and exacerbation frequency per year. Scores ranged from 0 (best status) to 3 (worst status) for $\mathrm{MRC}, 0-2$ for $\mathrm{FEV}_{1}$ and the exacerbation frequency, and 0 or 1 for smoking status. In the present study, the modified DOSE (mDOSE) index was calculated using the question "During the last year, how many severe or very unpleasant attacks of chest trouble have you had?" on the SGRQ, instead of exacerbation frequency over the previous year as indicated in the original manuscript. ${ }^{8}$ Points for each component were added so that the DOSE index ranged from 0 to 8 .

\section{Statistical analysis}

Results were expressed as mean \pm standard deviation, unless otherwise stated. Relationships between the mBODE, ADO, and mDOSE indices were analyzed by Spearman's correlation coefficient tests. The survival status of all patients after 5 years was assessed. The duration from entry to the last attendance or death was recorded. Univariate and multivariate Cox proportional hazards analyses were performed to investigate the relationships between the clinical measurements and mortality. Results of regression analyses were presented in terms of estimated relative risks (RR) with corresponding $95 \%$ confidence intervals. $P$-values of less than 0.05 were considered to be statistically significant.

\section{Results}

Baseline characteristics of the 150 male patients with stable COPD are shown in Table 1 and elsewhere. ${ }^{9}$ Their average age was $69 \pm 7$ years and the postbronchodilator $\mathrm{FEV}_{1}$ was $47.4 \% \pm 17.4 \%$ predicted. The frequency distributions of mBODE, ADO, and mDOSE scores are shown in Figure 1. The histograms showed widely and virtually normal distribution of the mBODE scores. The ADO scores were more narrowly distributed than the $\mathrm{mBODE}$ scores, with 55 patients (37\%) and 42 patients (28\%) scoring 3 and 4, respectively. The median of the mDOSE score was 2 , with the distribution

Table I Multidimensional staging of 150 male patients with chronic obstructive pulmonary disease

\begin{tabular}{lll}
\hline Characteristics & Mean \pm SD & Range \\
\hline mBODE index $(0-10)$ & $4.3 \pm 2.0$ & $0-9$ \\
ADO index $(0-10)$ & $3.8 \pm 1.2$ & $1-7$ \\
mDOSE index $(0-8)$ & $2.2 \pm 1.5$ & $0-6$ \\
\hline
\end{tabular}

Note: On the mBODE, ADO, and mDOSE indices, higher scores indicate a more severe status.

Abbreviations: $A D O$, age, dyspnea, and airflow obstruction; mBODE, modified body mass index, airflow obstruction, dyspnea, and exercise capacity; mDOSE, modified dyspnea, airflow obstruction, smoking status, and exacerbation frequency.
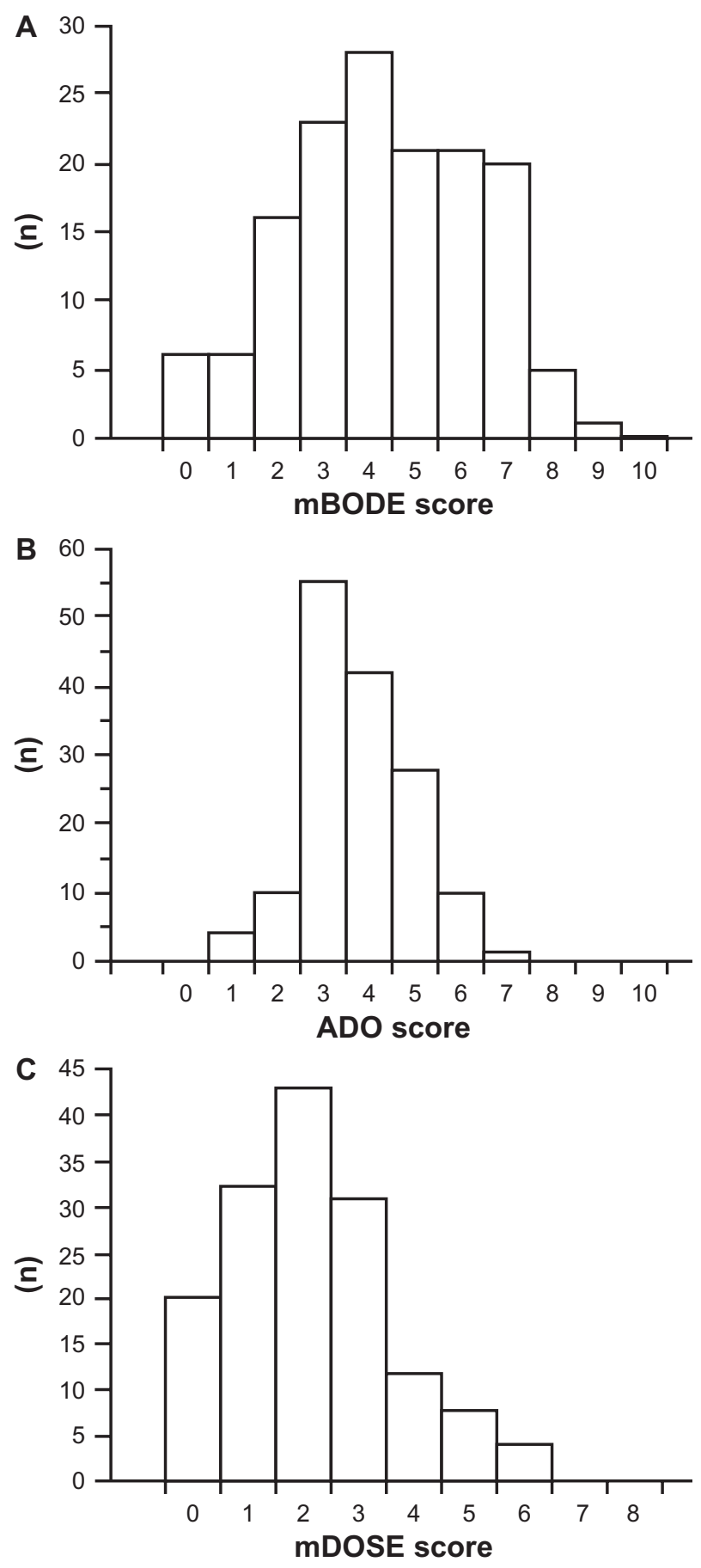

Figure I Frequency distributions of the (A) mBODE score, (B) ADO score, and (C) mDOSE score in patients with chronic obstructive pulmonary disease. In each, a higher score indicates a more severe status.

Abbreviations: ADO, age, dyspnea, and airflow obstruction; mBODE, modified body mass index, airflow obstruction, dyspnea, and exercise capacity; mDOSE, modified dyspnea, airflow obstruction, smoking status, and exacerbation frequency.

of scores tending to skew toward the lower scores. There were significant relationships between the three indices (mBODE vs ADO, correlation coefficients $\left[r_{\mathrm{s}}\right]=0.60$, $P<0.0001 ;$ ADO vs mDOSE, $r_{\mathrm{s}}=0.55, P<0.0001 ;$ and mDOSE vs mBODE, $\left.r_{\mathrm{s}}=0.64, P<0.0001\right)$. 
Of the 150 patients enrolled, six were unavailable for follow-up and 31 patients died. ${ }^{9}$ Causes of death were as follows: 20 due to COPD or COPD-related diseases, four due to malignant disorders (two lung cancer cases), one due to myocardial infarction and hepatic failure, respectively, and five due to unknown reasons.

Univariate Cox proportional hazards analyses were performed to investigate the relationship between clinical indices and mortality (Table 2 and elsewhere ${ }^{9}$ ). Age, BMI, $\mathrm{FEV}_{1}$, peak $\dot{\mathrm{V}}_{2}, \mathrm{MRC}$, and the SGRQ total score were all significantly related to mortality. All the mBODE, ADO, and mDOSE indices were strongly related to mortality $(\mathrm{RR}=1.618, P<0.0001 ; \mathrm{RR}=2.342, P<0.0001 ;$ and $\mathrm{RR}=1.521, P=0.0002$, respectively).

To investigate the abilities of the aforementioned three multidimensional staging methods to predict mortality as compared with airflow limitation, exercise capacity, dyspnea, and health status, multivariate Cox proportional hazards analyses were performed (Table 3). Model 1 includes three analyses investigating the relationships between each index and $\mathrm{FEV}_{1}$ with mortality. The mBODE and ADO indices were more significantly related to mortality than $\mathrm{FEV}_{1}$, but mDOSE index was not. Model 3 includes three analyses investigating the relationships between each index and MRC with mortality. The result was the same with Model 1 . These results indicate that predictive properties of $\mathrm{MBODE}$ and $\mathrm{ADO}$ indices might be stronger than those of $\mathrm{FEV}_{1}$ and $\mathrm{MRC}$ as well as mDOSE index. In contrast, Model 2 includes three analyses investigating the relationships between each index and peak $\dot{\mathrm{V}}_{2}$ with mortality. Peak $\dot{\mathrm{V}} \mathrm{o}_{2}$ was more significantly related to mortality than all three indices $(P<0.0001)$, indicating that the predictive property of exercise capacity might be stronger than different multidimensional staging. Model 4 includes three analyses investigating the relationships between each index and SGRQ with mortality. In contrast with Model 2, all three indices were more significantly related to mortality than the SGRQ total score.

To investigate which of the mBODE, ADO, and mDOSE indices was the most significantly correlated with mortality,

Table 2 Univariate Cox proportional hazards analyses in patients with chronic obstructive pulmonary disease

\begin{tabular}{llll}
\hline & Relative risk & 95\% confidence interval & P-value \\
\hline mBODE index & 1.618 & $1.301-2.013$ & $<0.000 \mathrm{I}$ \\
ADO index & 2.342 & $1.662-3.300$ & $<0.000 \mathrm{I}$ \\
mDOSE index & 1.521 & $1.223-1.890$ & 0.0002 \\
\hline
\end{tabular}

Abbreviations: $A D O$, age, dyspnea, and airflow obstruction; $\mathrm{mBODE}$, modified body mass index, airflow obstruction, dyspnea, and exercise capacity; mDOSE, modified dyspnea, airflow obstruction, smoking status, and exacerbation frequency. stepwise multivariate Cox proportional hazards analysis was performed (Table 4). Both the MBODE and ADO indices were significantly related to mortality $(\mathrm{RR}=1.351, P=0.027$; and $\mathrm{RR}=1.653, P=0.031)$ but not the mDOSE index $(P=0.87)$.

\section{Discussion}

We evaluated the predictive and discriminative properties of different multidimensional staging systems in patients with COPD. Among the mBODE, ADO, and mDOSE indices, the mBODE index seemed to have the best discriminative property. We found that all three indices were significantly predictive of mortality, although the predictive ability of the mDOSE tended to be inferior to the other two. In contrast, values for the peak $\dot{\mathrm{V}}_{2}$ on progressive cycle ergometry were more significantly correlated with mortality than any of the three multidimensional staging systems.

We previously examined predictors of mortality in patients with COPD and reported that exercise capacity, dyspnea, and health status were significantly related to mortality independently of airflow limitation..$^{9,20,21}$ These results suggested the need to incorporate these systemic elements in addition to $\mathrm{FEV}_{1}$ in evaluating patients with COPD. Among the three indices, the $\mathrm{mBODE}$ and $\mathrm{ADO}$ indices were more strongly predictive of mortality than $\mathrm{FEV}_{1}$, MRC, or SGRQ. Thus, these multidimensional staging systems seem to be more useful in prognostic assessments than airflow limitation, dyspnea, or health status alone in patients with COPD. After evaluating their properties well in different study situations, they will be used in clinical settings.

The relationships between the mBODE, ADO, and mDOSE indices were moderate, indicating that they do not necessarily evaluate the same aspects of COPD, although some components are common to all three indices. In fact, the stepwise multivariate Cox proportional hazards analysis showed that both the MBODE and ADO indices were independently related to mortality in patients with COPD. Thus, using more than one index might have some complementarily or additive advantage in prognostic assessment.

There were differences in the discriminative properties among the mBODE, ADO, and mDOSE indices. The mBODE score was more widely and normally distributed than the scores of the other indices examined, indicating its superior discriminative property. In our single population sample, the age component of the ADO index might have varied less widely than the original report of the ADO index, ${ }^{7}$ as shown here that about $65 \%$ of our patients scored 3 or 4 . Regarding the mDOSE index, firstly, its range from 0 to 8 is narrower than the BODE and ADO indices ranging 
Table 3 Multivariate Cox proportional hazards analyses in patients with chronic obstructive pulmonary disease

\begin{tabular}{|c|c|c|c|}
\hline \multicolumn{4}{|c|}{ Relative risk ( $95 \%$ confidence interval) } \\
\hline \multicolumn{4}{|c|}{ Model I (airflow limitation and multidimensional staging) } \\
\hline $\mathrm{FEV}_{1}$,\%pred & $0.972(0.935-1.012)$ & $0.967(0.936-0.998)^{\mathrm{a}}$ & $0.950(0.920-0.980)^{\mathrm{b}}$ \\
\hline mBODE index & $1.379(1.015-1.874)^{\mathrm{a}}$ & NA & NA \\
\hline ADO index & NA & $1.913(1.248-2.932)^{\mathrm{b}}$ & NA \\
\hline mDOSE index & NA & NA & $1.199(0.916-1.569)$ \\
\hline \multicolumn{4}{|c|}{ Model 2 (exercise capacity and multidimensional staging) } \\
\hline Peak $\dot{V}_{2}, \mathrm{~mL} / \mathrm{min}$ & $0.995(0.993-0.997)^{c}$ & $0.995(0.993-0.997)^{c}$ & $0.994(0.992-0.996)^{c}$ \\
\hline mBODE index & I.II3 (0.852-I.455) & NA & NA \\
\hline ADO index & NA & $1.328(0.889-1.983)$ & NA \\
\hline mDOSE index & NA & NA & I.I I9 (0.854-I.467) \\
\hline \multicolumn{4}{|c|}{ Model 3 (dyspnea and multidimensional staging) } \\
\hline MRC scale & $1.163(0.684-1.977)$ & $1.248(0.735-2.118)$ & $1.697(1.029-2.798)^{\mathrm{a}}$ \\
\hline mBODE index & $1.556(1.203-2.012)^{c}$ & NA & NA \\
\hline ADO index & NA & $2.082(1.334-3.249)^{\mathrm{b}}$ & NA \\
\hline mDOSE index & NA & NA & $1.263(0.955-1.670)$ \\
\hline \multicolumn{4}{|c|}{ Model 4 (health status and multidimensional staging) } \\
\hline SGRQ total & $1.014(0.990-1.039)$ & $1.019(0.997-1.042)$ & $1.014(0.987-1.04 I)$ \\
\hline mBODE index & $1.545(1.225-1.947)^{\mathrm{b}}$ & NA & NA \\
\hline ADO index & NA & $2.169(1.511-3.115)^{b}$ & NA \\
\hline mDOSE index & NA & NA & $1.384(1.037-1.845)^{\mathrm{a}}$ \\
\hline
\end{tabular}

Notes: ${ }^{\mathrm{a}} \mathrm{P}<0.05,{ }^{\mathrm{b}} \mathrm{P}<0.01,{ }^{\mathrm{c} P}<0.001$.

Abbreviations: $\mathrm{ADO}$, age, dyspnea, and airflow obstruction; $\mathrm{FEV}$, forced expiratory volume in I second; mBODE, modified body mass index, airflow obstruction, dyspnea, and exercise capacity; mDOSE, modified dyspnea, airflow obstruction, smoking status, and exacerbation frequency; MRC, Medical Research Council; NA, not applicable; SGRQ, St. George's Respiratory Questionnaire; $\dot{V}_{2}$, peak oxygen uptake.

from 0 to 10. Secondly, in the present study, the median score on the mDOSE index was low at 2 , and its distribution was skewed toward lower scores, which were consistent with the original report. ${ }^{8}$ Thus, although the ADO and DOSE indices are simple and easy assessments for use in primary care settings, as they do not include an exercise capacity component, their discriminative properties may be limited.

In the present study, peak $\dot{\mathrm{V}}_{2}$ was more strongly related to mortality than the mBODE, ADO, and mDOSE indices, indicating that peak $\dot{\mathrm{VO}}_{2}$ is an important factor in COPD in relation to mortality. In addition to studies examining predictors of mortality in $\mathrm{COPD},{ }^{9}$ peak $\mathrm{V}_{2}$ is reported to be a useful prognostic factor in other disorders ${ }^{22,23}$ such as interstitial lung diseases,${ }^{24}$ primary pulmonary hypertension, ${ }^{25}$ cyctic fibrosis, ${ }^{26}$ or chronic heart failure. ${ }^{27}$ Cardiopulmonary exercise testing has some utility in diagnosis and functional evaluation, and prognostic stratification is considered to be

Table 4 Stepwise multivariate Cox proportional hazards analysis in patients with chronic obstructive pulmonary disease

\begin{tabular}{llll}
\hline & Relative risk & 95\% confidence interval & $P$-value \\
\hline mBODE index & $1.35 \mathrm{I}$ & $1.035-1.765$ & 0.027 \\
ADO index & 1.653 & $1.047-2.610$ & 0.031 \\
mDOSE index & & & 0.87 \\
\hline
\end{tabular}

Abbreviations: $A D O$, age, dyspnea, and airflow obstruction; $\mathrm{mBODE}$, modified body mass index, airflow obstruction, dyspnea, and exercise capacity; mDOSE, modified dyspnea, airflow obstruction, smoking status, and exacerbation frequency. a major indication for cardiopulmonary exercise testing in patients with pulmonary or cardiac disorders. ${ }^{23}$

In the present study, we compared different multidimensional staging systems from the viewpoint of the relationship of their scores with mortality. Although these or similar indices are sometimes referred to as disease severity indices, strictly speaking, disease severity in COPD has not been defined. When disease severity is considered according to the closeness of death, assessing results of these systems would be appropriate in predicting mortality. However, there are other ideas about defining disease severity, such as its relationship with health status or exacerbations. It seems that multidimensional staging is superior to the current means of disease staging based on the level of $\mathrm{FEV}_{1} \cdot{ }^{28,29} \mathrm{~A}$ standardized definition of disease severity is needed to eliminate confusion and to officially establish a novel disease severity staging system not based solely on $\mathrm{FEV}_{1}$ in future.

As a limitation, although several multidimensional staging systems in addition to the BODE, ADO, and DOSE indices have been developed in recent years, ${ }^{30,31}$ we did not assess them in the present study.

\section{Conclusion}

We demonstrated that the multidimensional staging systems of the mBODE, ADO, and mDOSE indices were significant predictors of mortality in patients with COPD. The mBODE 
was superior to other indices for its discriminative property. An understanding of the properties or characteristics of the indices is important when using them in clinical practice, and, at the same time, a definition of disease severity needs to be established in order to propose the indices assessed in this report as a new disease severity index.

\section{Disclosure}

The authors declare that they had no competing interests.

\section{References}

1. Global Initiative for Chronic Obstructive Lung Disease. Global strategy for the diagnosis, management, and prevention of chronic obstructive pulmonary disease. Available at: http://www.goldcopd.com (last accessed September 20, 2011).

2. Standards for the diagnosis and care of patients with chronic obstructive pulmonary disease. American Thoracic Society. Am J Respir Crit Care Med. 1995;152:S77-S121.

3. Optimal assessment and management of chronic obstructive pulmonary disease (COPD). The European Respiratory Society Task Force. Eur Respir J. 1995;8:1398-1420.

4. Celli BR, MacNee W; ATS/ERS Task Force. Standards for the diagnosis and treatment of patients with COPD: a summary of the ATS/ ERS position paper. Eur Respir J. 2004;23:932-946.

5. Celli BR, Cote CG, Marin JM, et al. The body-mass index, airflow obstruction, dyspnea, and exercise capacity index in chronic obstructive pulmonary disease. $N$ Engl J Med. 2004;350:1005-1012.

6. Cote CG, Celli BR. BODE index: a new tool to stage and monitor progression of chronic obstructive pulmonary disease. Pneumonol Alergol Pol. 2009;77:305-313.

7. Puhan MA, Garcia-Aymerich J, Frey M, et al. Expansion of the prognostic assessment of patients with chronic obstructive pulmonary disease: the updated BODE index and the ADO index. Lancet. 2009;374:704-711.

8. Jones RC, Donaldson GC, Chavannes NH, et al. Derivation and validation of a composite index of severity in chronic obstructive pulmonary disease: the DOSE Index. Am J Respir Crit Care Med. 2009;180:1189-1195.

9. Oga T, Nishimura K, Tsukino M, et al. Analysis of the factors related to mortality in chronic obstructive pulmonary disease: role of exercise capacity and health status. Am J Respir Crit Care Med. 2003;167:544-549.

10. Oga T, Nishimura K, Tsukino M, et al. The effects of oxitropium bromide on exercise performance in patients with stable chronic obstructive pulmonary disease. A comparison of three different exercise tests. Am J Respir Crit Care Med. 2000;161:1897-1901.

11. Oga T, Nishimura K, Tsukino M, et al. Exercise capacity deterioration in patients with COPD: longitudinal evaluation over 5 years. Chest. 2005;128:62-69.

12. American Thoracic Society; American College of Chest Physicians. ATS/ACCP statement on cardiopulmonary exercise testing. Am J Respir Crit Care Med. 2003;167:211-277.

13. Jones NL, Makrides L, Hitchcock C, et al. Normal standards for an incremental progressive cycle ergometer test. Am Rev Respir Dis. 1985;131:700-708.

International Journal of COPD

\section{Publish your work in this journal}

The International Journal of COPD is an international, peer-reviewed journal of therapeutics and pharmacology focusing on concise rapid reporting of clinical studies and reviews in COPD. Special focus is given to the pathophysiological processes underlying the disease, intervention programs, patient focused education, and self management protocols.
14. Oga $\mathrm{T}$, Nishimura $\mathrm{K}$, Tsukino $\mathrm{M}$, et al. Longitudinal deteriorations in patient reported outcomes in patients with COPD. Respir Med. 2007;101:146-153.

15. Hajiro T, Nishimura K, Tsukino M, et al. Analysis of clinical methods used to evaluate dyspnea in patients with chronic obstructive pulmonary disease. Am J Respir Crit Care Med. 1998;158:1185-1189.

16. Jones PW, Quirk FH, Baveystock CM, Littlejohns P. A selfcomplete measure of health status for chronic airflow limitation: the St. George's Respiratory Questionnaire. Am Rev Respir Dis. 1992;145:1321-1327.

17. Hajiro T, Nishimura K, Tsukino M, et al. Comparison of discriminative properties among disease-specific questionnaires for measuring healthrelated quality of life in patients with chronic obstructive pulmonary disease. Am J Respir Crit Care Med. 1998;157:785-790.

18. Cote CG, Pinto-Plata VM, Marin JM, et al. The modified BODE index: validation with mortality in COPD. Eur Respir $J$. 2008;32:1269-1274.

19. Cardoso F, Tufanin AT, Colucci M, et al. Replacement of the 6-min walk test with maximal oxygen consumption in the BODE index applied to patients with COPD: an equivalency study. Chest. 2007;132:477-482.

20. Nishimura K, Izumi T, Tsukino M, Oga T. Dyspnea is a better predictor of 5-year survival than airway obstruction in patients with COPD. Chest. 2002;121:1434-1440.

21. Oga T, Nishimura K, Tsukino M, et al. Dyspnoea with activities of daily living versus peak dyspnoea during exercise in male patients with COPD. Respir Med. 2006;100:965-971.

22. ERS Task Force. Recommendations on the use of exercise testing in clinical practice. Eur Respir J. 2007;29:185-209.

23. Ferrazza AM, Martolini D, Valli G, Palange P. Cardiopulmonary exercise testing in the functional and prognostic evaluation of patients with pulmonary diseases. Respiration. 2009;77:3-17.

24. Miki K, Maekura R, Hiraga T, et al. Impairments and prognostic factors for survival in patients with idiopathic pulmonary fibrosis. Respir Med. 2003;97:482-490.

25. Wensel R, Opitz CF, Anker SD, et al. Assessment of survival in patients with primary pulmonary hypertension: importance of cardiopulmonary exercise testing. Circulation. 2002;106:319-324.

26. Nixon PA, Orenstein DM, Kelsey SF, Doershuk CF. The prognostic value of exercise testing in patients with cystic fibrosis. $N$ Engl J Med. 1992;327:1785-1788.

27. Corrà U, Mezzani A, Bosimini E, Giannuzzi P. Cardiopulmonary exercise testing and prognosis in chronic heart failure: a prognosticating algorithm for the individual patient. Chest. 2004;126:942-950.

28. Funk GC, Kirchheiner K, Burghuber OC, Hartl S. BODE index versus GOLD classification for explaining anxious and depressive symptoms in patients with COPD: a cross-sectional study. Respir Res. 2009;10:1.

29. Funk GC, Kirchheiner K, Burghuber OC, Hartl S. Classifying the severity of COPD: are the new severity scales better than the old? Int J Tuberc Lung Dis. 2009;13:783-790.

30. Briggs A, Spencer M, Wang H, et al. Development and validation of a prognostic index for health outcomes in chronic obstructive pulmonary disease. Arch Intern Med. 2008;168:71-79.

31. Esteban C, Quintana JM, Aburto M, et al. A simple score for assessing stable chronic obstructive pulmonary disease. QJM. 2006;99:751-759

This journal is indexed on PubMed Central, MedLine and CAS. The manuscript management system is completely online and includes a very quick and fair peer-review system, which is all easy to use. Visit $\mathrm{http}: / /$ www.dovepress.com/testimonials.php to read real quotes from published authors. 